\title{
Dependence From The Perspective Of Primary Caregivers Of People With Disabilities
}

\author{
José-Manuel Quesada-Rubio, University of Granada, Spain \\ Marta Ortega-Ortega, University of Granada, Spain \\ Valentín Molina-Moreno, University of Granada, Spain \\ Ignacio Ruiz-Guerra, University Complutense of Madrid, Spain \\ María-Dolores Huete-Morales, University of Granada, Spain
}

\begin{abstract}
The paper is focused on informal caregivers of people with disabilities, particularly in mentally handicapped persons. Informal caregiver refers to those relatives, friends or any person who make this task without any formal economic remuneration. Only in few cases, caregivers are able to receive some economic aid by the administration.
\end{abstract}

We develop a questionnaire to analyze personal, familiar, economic and social situation of primary caregivers. The empirical results are based on a sample of 128 caregivers of a spanish association created for people with disabilities.

Keywords: Dependence; Quality of Life; Disability

\section{INTRODUCTION}

Ce follow the definition according to the Dictionary of the Spanish Royal Academy (2001) which says that "disability" is the condition for certain people who have problems in the use of a bodily function, sensory or intellectual means a disadvantage for its development in the social and relationship with others. In this sense, we understand that disability decreases the possibilities of autonomy in the daily life of the person.

The National Statistics Institute of Spain registered approximately 3,85 million people with disabilities, both physical and intellectual or sensory impairments, in 2008. However, depending on the type of disability, whether physical, intellectual, sensory or mental disability, the need of daily assistance required by the individual is different. We focused our research on intellectual disabilities which is one of the most restricting.

However, the concept intellectual disability is not defined as such. At present the concept used is that proposed by the AAMR (American Association on Mental Retardation) in 1992: "Intellectual disability is a disability characterized by significant limitations in intellectual functioning both in adaptive and behavior, which covers everyday many social and practical skills. This disability originates before 18 years old". It refers to overall mental capacities, such as learning, reasoning, problem solving, and so on (conceptual skills, social skills and practical skills). So, this kind of limitations reduces the autonomy and in the most of the situations intellectual disability people need support or supervision of another person every day, in other words, they are "dependents". Disability is closely related to human dependency. 


\section{INFORMAL PRIMARY CAREGIVERS}

"Informal caregiver's" term was born attached to the term of "dependence". Dependence can be understood as the result of a process that begins with the appearance of deficits in physical functioning due to illness or accident, this implies limits in the normal activity, when this limitation can't be offset by the adoption of environment causes a restriction on participation as embodied in the dependence on aid from others to perform activities of daily living (Ministerio de Trabajo y de Asuntos Sociales de España, 2004).

The survey data on disability from the National Institute of Statistics of Spain "Survey of disability situations of personal autonomy and dependence" confirms that relatives are those who take care of dependents, through which appeared the term informal support (INE, 2009).

In this sense, we can distinguish between two types of caregivers: formal and informal caregivers. According to Lopez-Gil (2009) formal caregivers are those who are hired specifically to care for and assist the individual in need, formally receiving financial remuneration. However, informal caregivers are family members or friends who voluntarily and without any financial compensation take care of basic needs and instrumental daily living at the family member or friend who needs it.

However, the system based on this informal support can't be sustained over the medium term in a society like the present. This is because of demographic reasons in which families have increasingly fewer members due to the decrease of birth and social transformation family subject to different pressures and relational changes over previous decades. That is why is growing a new kind of economy, it is the Social Economy which aim is to reply society's demands. In Spain, there are cooperative social services and intermediary services related to the disability sector. However, the protection's system of informal caregivers of dependent people is still a subject rarely treated in our country.

This issue is highly important, especially if we follow the National Institute of Statistics of Spain which shows that almost half of disabled people need to be attended for eight or more hours per day (INE, 2009). It is more significant for people with intellectual disabilities, where almost two-thirds of them, require the maximum personal attention. We can appreciate that the role of caregiver is essential for these people.

According to the "Survey of disability situations of personal autonomy and dependence" in Spain, the $73,6 \%$ (AGE, 2008) of cases of dependence, the women is who exercise the role of informal caregivers. It is also reflected in the studies written by Turnbull, Summers, Lee and Kyzar (2007) and Chou, Pu, Kröger, and Fu (2010). In addition, the literature suggests that informal care will impact both positive (feeling of well being generated by the work, narrow bond between the caregiver and the disabled) and negative (physical and psychological overload) on the informal caregiver (Schulz and Beach, 1999; Chou, Lin, Chang, and Schalock, 2007).

Therefore, the functions performed by social economy organizations are essential in a society whose aim is social progress. Associations such as ASPROGRADES (Association for Persons with Intellectual Disability), which is based our study not only enhance the quality of life of employees, in this case intellectual disabilities, but also improve the welfare of their primary caregivers informal and family, reducing the effort and time spent in their wards, which can be devoted to other personal activities.

Our main goal is to understand the socioeconomic characteristics of informal caregivers of people with a disability, particularly intellectual disability. Also, understanding the impact caused labor and time devoted to family care or ward to be provided by both the informal caregiver ASPROGRADES association.

\section{TOOLS AND METHODOLOGY}

We focused our analysis on the major center of social economy for people with intellectual disabilities in the province of Granada (Spain). It is ASPROGRADES's association. It is a nonprofit association composed by people with intellectual disabilities, their families and associates volunteers. It belongs to the Spanish Confederation of Organizations for Persons with Intellectual Disability (FEAPS) and receives in its centers to 270 people with intellectual disabilities in the province. 
ASPROGRADES born in August 1964 and was declared of public utility and social interest in 1966 (in compliance with the rules of the law 49/2002), thanks to the work of a group of parents whose children did not have proper educational care and integration society. Currently, the association has three centers: a College of Special Education, aimed at providing education to pupils aged 3 to 20 years; Occupational Center with Day Stay Unit and finally the headquarters of the association in which join a center with Occupational Therapy Service, a special employment center and a nursing home.

However, the work of APROGRADES not directed only to improve the quality of life of mentally disabled people, but also of informal caregivers (family or guardian), which receive functional support, and psychological important part of that association. Therefore, our goal is to make a descriptive analysis that allows us to identify the main personal characteristics, family, economic and social informal caregivers' primary intellectual disability.

We produced a questionnaire for ASPROGRADES's caregivers. Social workers of ASPROGRADES center conducted an information session for parents, guardians or family caregivers of the users to explain the objectives of the study. Questionnaires were referred back to the center. The situations in which caregivers were too old or sensed that social workers may have difficulty understanding the questionnaire, were quoted by the center for joint implementation. The process of distribution of questionnaires took place during the first quarter of 2012. 128 questionnaires were received. Questionnaires developed are based on the existence of the caregivers support their relatives in some of the next activities (Querejeta, 2004):

- $\quad$ Basic activities of daily living (ADL): They are essential to survive independently. For example washing, dressing, just the service, recognizes people and objects, navigating, understanding and executing instructions, etc.

- Instrumental activities of daily living (IADL): Its realization requires a higher level of personal autonomy. They are associated with tasks involving the ability to make decisions more difficult and involve interactions with the environment.

\section{RESULTS ANALYSIS}

And so, it is created a database based on the responses from participants, and descriptive analysis was performed with the statistical program SPSS Statistics 20.0. Descriptive statistics of frequency of quantitative and qualitative variables studied.

The response rate obtained was $47,40 \%(\mathrm{n}=128)$. From our results we can say that the average age of informal caregivers is 58,5 years old being the maximum 91 years. The 50,79\% of respondents have between 40 and 60 years old (Figure 1). They have a basic education level, the 22,66\% have incomplete primary education and $24,22 \%$ have been completed (figures not included). Importantly, the vast majority of informal caregivers are women $(89,1 \%)$. Furthermore, in $75,78 \%$ of cases, the relationship with the patient revolves around the figure of the mother (Figure 1). Regarding the status of informal caregivers, they are mostly married or they live with a partner $(60,94 \%)$, subsequently followed by the widowers with a representative rate of $21,88 \%$. It is noted that $100 \%$ of divorced and separated respondents (11.71\%) are women. This could be due to the dissolution of the couple, which usually awarded custody of children to women, given that historically has been the woman in charge of home and family (figures not included).

Delving into the care provided by informal caregivers to the mentally disabled, we find that the average time that the informal caregivers are caring for the user is 25,7 years (min. 2 years max. 62 years) as we can see in Figure 1 . However, only $24,14 \%$ receive any financial remuneration from the public administration, with an average of $420,5 € /$ month (min. $€ 173 € /$ month, max. $780 € /$ month). Nevertheless, the informal caregiver spends an average of 169,2 minutes per day (2.8 hours) to help perform the basic tasks of daily living to people with intellectual disabilities, spending more time cooking and basic hygiene help, dressing and change, as noted in the chart. We can see this in Figure 2. Also, they spend an average of 54,4 hours per week in aid of instrumental activities of daily living, paying greater attention to monitoring and supervision of the disabled and the performance of household chores. This reflects an important commitment by the informal caregiver. 
In turn, the $10,32 \%$ of informal caregivers, say they have hired additional person (formal caregivers) to aid in the care of his family or ward, an average of 12 hours per week (min. 2 h. - max. 40 h.). Furthermore, $80 \%$ of users come to the center ASPROGRADES 35 hours. This makes sense, since 48.4\% of the center's users have a high degree of disability ( $76 \%-100 \%$ of depreciation), and 57,3\% also presents other additional intellectual disability, such as sensorial, mental or physical. The average age of the disabled in our center is 31 years (min. 7 years - max. 64 years) (figures not included).
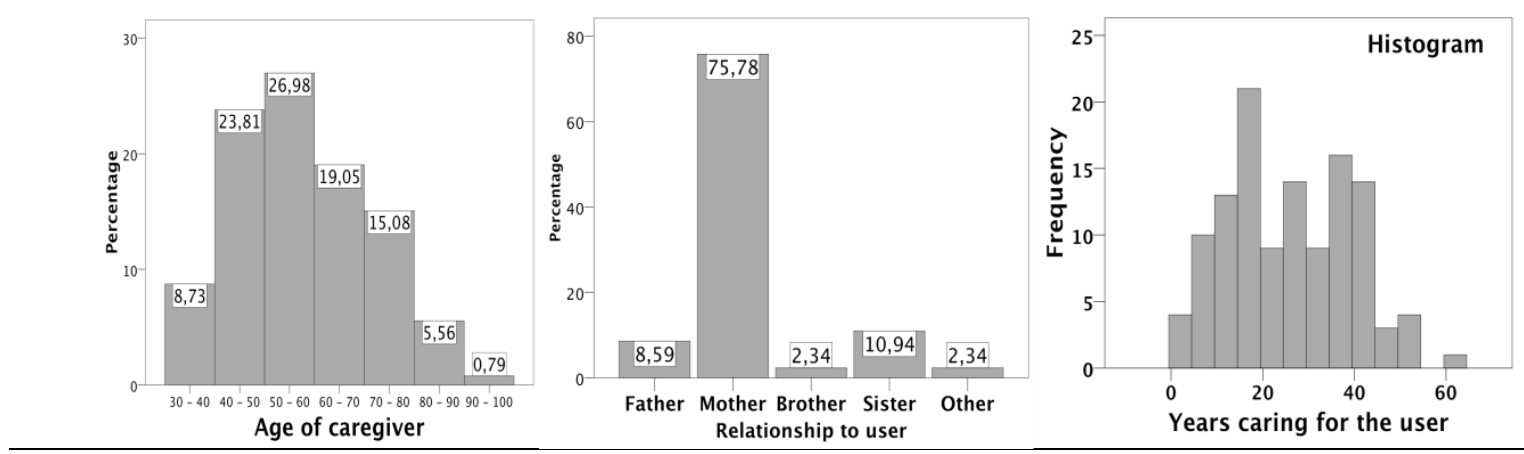

Figure 1

Source: own elaboration
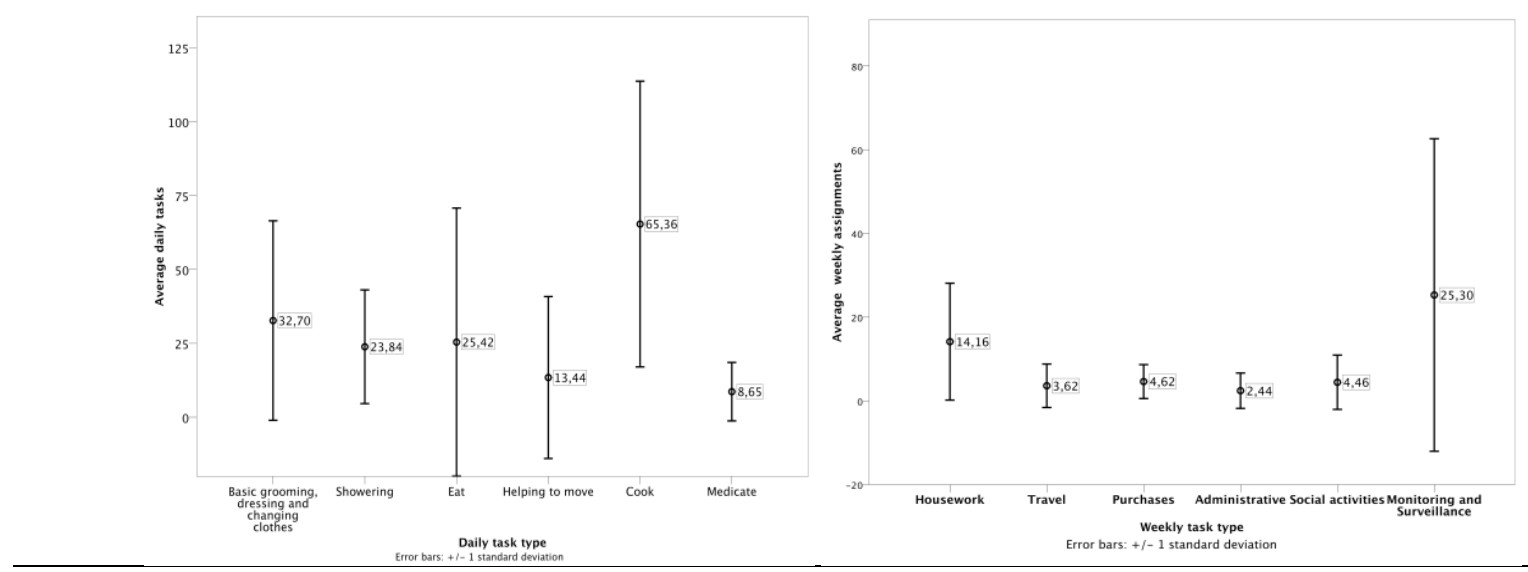

Figure 2

Source: own elaboration

As we can see in Figure 3, the average family net income, taking into account the earnings of all persons living in the home, at $63,94 \%$ does not exceed 1.500 euros per month. In this sense we consider the economic benefit received by the patient by the social services, where $97,7 \%$ of users receive some help, coming in $56,8 \%$ of the Social Security system of Spain. The average amount of finance help received by the users is between 400 and 600 euros per month in $46,72 \%$ of cases. It should be noted the important efforts made by caregivers towards improving the quality of life of his family or ward. The results show that $20,34 \%$ of caregivers had to retire early or leave the job in which they were. Currently, $20,83 \%$ of caregivers are employed, $15 \%$ unemployed, $27,5 \%$ were housewives and $32,5 \%$ were retired (Figure 3 ). 

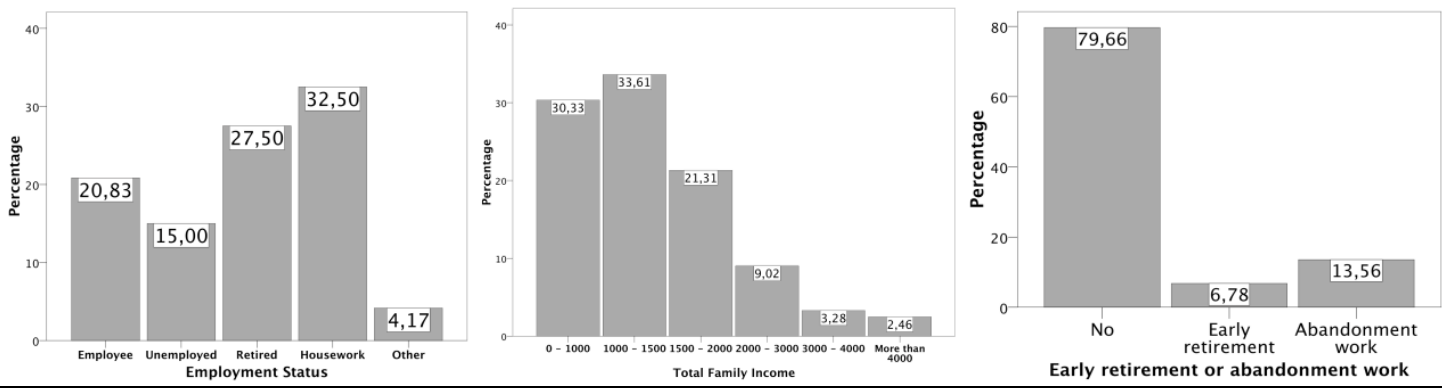

Figure 3

Source: own elaboration

Finally it should be noted the important work of social economy organizations, as presented in this work make to improve the well being of the disabled and their families. So in one last question asked caregivers are asked to rate from 1 to 5 how necessary it is believed that the social work done ASPROGRADES about informal caregivers, where 1 to 5 completely unnecessary and necessary. The results show us once again the invaluable work for the welfare of caregivers and thus of the disabled, with an average of 4,93 (figure not included).

\section{CONCLUSIONS}

Associations for persons with disabilities as ASPROGRADES association, not only exert a significant work for the user of the center allowing the development of personal capabilities and their social integration, but are a fundamental and essential support for families of these people, especially for informal caregiver.

We have observed that the average age of the informal caregiver is 58,52 years old. The 50,7\% of them are between 40 and 60 years old and they are doing the work of informal caregivers an average of 25,7 years. The $89,1 \%$ of informal caregivers are women and approximately $60 \%$ are married or cohabiting. The $24,2 \%$ of them have completed primary studies, and almost the same number haven't finished them (22,7\%). These results are validated and consistent with the literature (INE, 2009). In regard to occupation reflected by our caregivers, $60 \%$ were housewives or retired. However, it is interesting to reflect that $20,34 \%$ of caregivers who were working, had to leave their jobs or retiring early to assist his family dependent. This is a significant loss of labor productivity for society interesting to analyze for future research.

It should be noted that informal caregivers spend an average of 169.2 minutes per day (2,8 hours) to help perform the basic tasks of daily life, devoting more time to cook. Likewise, spend an average of 54.4 hours per week to help to carry out instrumental activities of daily living, needing more time in monitoring and supervision. This data is very representative, since $48 \%$ of caregivers assist people with intellectual disabilities whose degree of disability is between $75 \%$ and $100 \%$. However, only $24,14 \%$ of these informal caregivers, receive some financial remuneration from the public administration, with an average $420 € /$ month.

If we recalculate the number of hours per month that informal caregivers involved in helping and serving the mentally disabled, we get an average of 301,6 hours. To get an idea, the full working day in Spain is 8 hours each day during 5 or 6 days. This means 160-192 hours per month, much less than informal caregivers.

Regarding formal care, such as those offered by ASPROGRADES center, it welcomes disabled half of 33,65 hours per week, representing a major break for families and caregivers who can devote those hours to other tasks. The economic contribution to the center of the $95,7 \%$ of respondents is less than $200 € /$ month, whose net income are between 1000 and $1500 € /$ month in the $33,6 \%$ of the cases.

We observe a significant burden on informal caregivers functional, despite the assistance offered by centers of social economy as we have been presented in the article. It is therefore manifest that caregivers support the vital work of the social economy entities as ASPROGRADES, bring to society and its users in order to improve the lives of the disabled people and their families. 


\section{AUTHOR INFORMATION}

Jose Manuel Quesada Rubio, Ph.D. Mathemátics. Professor in University of Granada. Main areas of research interest: statistics and operative research. E-mail: quesada@ugr.es (Corresponding author)

Marta Ortega Ortega, Grade on Economics. Pre Ph.D. on Health Economics. Professor in University of Granada. Main areas of research interest: economic evaluation of health technology, quality of life and disability.

Valentín Molina Moreno, Ph.D. on Social Economics and Business. Professor in University of Granada. Main areas of research interest: social corporative responsability, social economy and disability.

Ignacio Ruiz Guerra, Ph.D. on Economics. Professor Complutense University of Madrid. Main areas of research interest: internationalization and local development.

María Dolores Huete Morales, Ph.D. on Mathematics. Professor in University of Granada. Main areas of research interest: demographic statistic and development.

\section{REFERENCES}

1. Chou, Y. C., Lin, L. C., Chang, A. L., and Schalock, R. L. (2007). The quality of life of family caregivers of adults with intellectual disabilities in Taiwan. Journal of Applied Research in Intellectual Disabilities, 20 (3), 200-210.

2. Chou, Y. C., Pu, C.Y., Kröger, T. and Fu, L.Y. (2010). Caring, Employment, and Quality of Life: Comparison of Employed and Nonemployed Mothers of Adults With Intellectual Disability. American Journal on Intellectual and Developmental Disabilities 115(5), 406-420.

3. Diccionario de la Real Academia Española (2001). $2^{\circ}$ edición.

4. $\quad$ EDAD (2008). http://www.ine.es/jaxi/menu.do?type=pcaxis\&path=\%2Ft15\%2Fp418\&file=inebase

5. FEAPS (2010). Discapacidad intelectual y envejecimiento: Un problema social del siglo XXI. Colección FEAPS, $n^{\circ} 12$, Madrid: FEAPS

6. INE (2009). Panorámica de la discapacidad en España: Encuesta de discapacidad autonomía personal y situaciones de dependencia. Boletín informativo del Instituto Nacional de Estadística, 10/2009.

7. López-Gil, M.J., Orueta-Sánchez, R., Gómez-Caro, S., Sánchez-Oropesa, A., Carmona de la Morena, J., Alonso-Moreno, F.J. (2009). El rol de cuidador de personas dependientes y sus repercusiones sobre su calidad de vida y su salud. Revista Clinica de Medicina Familiar, 2 (7), 332-334.

8. Ministerio de Trabajo y Asuntos Sociales de España (Ed.) (2004): Atención a las personas en situación de dependencia en España. Libro Blanco, Madrid.

9. Querejeta, M. (2004). Aportaciones de la CIF a la conceptualización de la Dependencia. Revista de Rehabilitación, 38 (6), 248-54.

10. Schulz, R. and Beach, S.R. (1999). Caregiving as a risk factor for mortality: the Caregiver Health Effects Study. JAMA, 282, 2215-2219.

11. Turnbull, A.P., Summers, J.A., Lee, S.H., and Kyzar, K. (2007). Conceptualization and measurement of family outcomes associated with families of individuals with intellectual disabilities. Mental Retardation and Development Disabilities Research Reviews, 13(4), 346-356. 